\title{
Depressive, anxiety, and post-traumatic stress symptoms affecting hospitalized and home-isolated COVID-19 patients: a comparative cross-sectional study
}

\author{
Amany Elshabrawy Mohamed ${ }^{*}$ and Amira Mohamed Yousef
}

\begin{abstract}
Background: Coronavirus has affected more than 100 million people. Most of these patients are hospitalized in isolation wards or self-quarantined at home. A significant percentage of COVID-19 patients may experience psychiatric symptoms. This study attempts to assess depressive, anxiety, and post-traumatic stress symptoms in home-isolated and hospitalized COVID-19 patients, besides whether the isolation setting affected these symptoms' presentation.

Results: The study involved 89 patients with confirmed COVID-19 virus, and the patients were divided into 2 groups: 43 patients in the home-isolated group (group A) and 46 patients in the hospital-isolated group (group B). The majority of subjects were male and married; also, they were highly educated. 30.2\% from group A and $47.8 \%$ from group B had a medical occupation. There was a statistically significant difference $(p=0.03)$ between both groups in the presence of chronic disease. There was a statistically significant increase in suicidal thoughts in the home-isolated group (37.2\%) $\left(p=0.008^{* *}\right)$. We found a statistically significant increase in the abnormal scores of Hospital Anxiety Depression Scale-Depression (HADS-Depression) in the home-isolated group (69.7\%) compared to the hospital-isolated group (32.6\%) $\left(p<0.001^{* *}\right)$ which denotes considerable symptoms of depression. Moreover, we found that (32.6\%) from the home-isolated group and (39.1\%) from the hospital-isolated group had abnormal scores of Hospital Anxiety Depression Scale-Anxiety (HADS-Anxiety) which denotes considerable symptoms of anxiety. Also, we found $66.7 \%$ and $87.2 \%$ scored positive by the Davidson Trauma Scale (DTS) in the home-isolated group and hospital-isolated group, respectively. Which was statistically significant $\left(p=0.02^{* *}\right)$. On doing a binary logistic regression analysis of HADS and DTS with significantly related independent factors, we revealed that lower education levels and family history of psychiatric disorder were risk factors for abnormal HADS-Anxiety scores in COVID-19 patients. The medical occupation was a protective factor against having abnormal HADS-Depression scores in COVID-19 patients, while home isolation was a risk factor. On the contrary, the medical occupation was a risk factor for scoring positive in DTS in COVID-19 patients. Simultaneously, low levels of education and home isolation were protective factors.
\end{abstract}

Conclusion: A significant number of patients diagnosed with the COVID-19 virus develop depressive, anxiety, and post-traumatic stress symptoms, whether they were isolated in the hospital or at home; besides, the isolation setting may affect the presenting symptoms.

Keywords: COVID-19, Psychiatric symptoms, Isolation

* Correspondence: Ahmed2001go@yahoo.com

Psychiatry Department, Faculty of Medicine, Zagazig University, Zagazig,

Egypt

(c) The Author(s). 2021 Open Access This article is licensed under a Creative Commons Attribution 4.0 International License, which permits use, sharing, adaptation, distribution and reproduction in any medium or format, as long as you give appropriate credit to the original author(s) and the source, provide a link to the Creative Commons licence, and indicate if changes were made. The images or other third party material in this article are included in the article's Creative Commons licence, unless indicated otherwise in a credit line to the material. If material is not included in the article's Creative Commons licence and your intended use is not permitted by statutory regulation or exceeds the permitted use, you will need to obtain permission directly from the copyright holder. To view a copy of this licence, visit http://creativecommons.org/licenses/by/4.0/. 


\section{Background}

Diseases triggered by viral infections are predominant, and some are known to cause neuropsychiatric disorders involving cognitive, affective, behavioral, and perceptual symptoms [1].

Scientists found multiple cases of atypical pneumonia in Wuhan, China, in December 2019, and WHO later discovered a virus called SARS-coronavirus 2. (SARSCoV-2) had inflicted these effects [2].

More than 50 million victims of COVID-19 have been affected. Many of these patients are hospitalized in advanced and segregated hospitals or isolated in their residences. Those afflicted with a novel and potentially lethal disease feel terrified, rage, and anxious for friends' and families' health [3].

Early literature investigated the respiratory manifestations of COVID-19 patients; nevertheless, evolving data indicate that neuropsychiatric illnesses have been elevated in a significant number of patients, particularly those with severe infection [4,5]. A joint case series documenting neuropsychiatric symptoms in 153 patients suggested that a compromised mental state was the most predominant presentation in the sample population. However, this study did not investigate the initial psychiatric manifestations, such as depression and anxiety $[6,7]$.

Generally, there has been milieu research concerning the epidemiological impact on the populace, not in those subjected to SARS-2-CoV directly [7, 8]. However, the literature on COVID-19 patients indicates elevated rates of anxiety as well as depression in this group [8].

Hospitalized COVID-19 patients could be demographically at higher risk of experiencing psychiatric symptoms due to their serious illness, the stress of staying in isolation whilst hospitalized, in addition to the potential side effects of drugs as well as treatments. On the contrary, patients isolated at home may also be prone to developing specific psychiatric symptoms, which may be illustrated through the dissemination dynamics of COVID-19 that parallel with dehumanizing reports of widely used social networks that led to increased selfperceived post-traumatic stress, suicidality, and other psychological symptoms [7, 9]. In addition to being alone, even at home, with negative emotions such as functional disability, stigma, anxiety, phobia, irritation, and resentment may be a trigger factor for developing psychiatric symptoms [9].

COVID-19 is marked by its expansion beyond the officially affiliated health organizations. The requisite restricting procedures resulted in a daunting situation where anxiety and confusion prevailed [10], in addition to the apprehension of mortality upon infection, stigmatization, and prejudice for COVID-19 patients. In addition to fear of infecting others may induce various psychiatric symptoms [11]. These symptoms may increase when isolated at home and with close contact with their relatives and not under direct and immediate medical treatment.

Environmental pressure in lockdown, difficulty breathing, and other types of complaints in patients during the COVID-19 disease outbreak caused a wide range of psychiatric disorders similar to SARS [12]. These circumstances caused the secretion of stressor-dependent corticotrophin-releasing hormone $(\mathrm{CRH})$ from hypothalamic paraventricular nucleus (PVN) neurons as well, which binds to its receptors in the anterior pituitary gland causing stimulation of the hypothalamic-pituitaryadrenal (HPA) axis) [12], besides causing elevated ACTH levels, which in turn leads to elevated concentrations of glucocorticoids [13]. When a high concentration of glucocorticoids is released and binds to glucocorticoid receptors (GR) in the brain, hyper-activation of the HPA axis causes stress-related gene expression [14]. Hyperactivation of the HPA axis and dysfunction in the stressrelated gene lead to increased exposure to environmental stress [15]. Environmental stress can alter the epigenetics of SERT, BDNF, GR, FKBP5, and CRHR1 genes via multiple mechanisms and induces transcriptional changes of these gene expressions, resulting in stressrelated disorders [16]. Thus, the extreme stressful environment caused by COVID-19 can lead to an increased psychiatric disorder.

Moreover, SARS-CoV-2 can also affect brain tissue by causing a cytokine storm, which is believed to affect psychiatric symptoms [17]. The researchers assumed that the low-grade inflammatory response might be crucial to the psychiatric symptoms of COVID-19 infection [18]. To date, it cannot be determined whether or not the virus has an independent effect on inflammation and mental health [19].

We aimed to assess depressive, anxiety, and posttraumatic stress symptoms in home-isolated and hospitalized COVID-19 patients, besides whether the isolation setting affected these symptoms' presentation.

\section{Methods}

\section{Study design and setting}

The current study is a comparative cross-sectional study on the Sharkia Governorate, where patients were recruited from Zagazig University Hospitals' isolation hospital. The isolated home patients were residents of Sharkia Governorate, Egypt, between 22 May 22 and 28 July 2020.

\section{Study participants}

Eighty-nine subjects were recruited in this study and were divided into two groups: 43 home-isolated patients (group A) and 46 hospital-isolated patients (group B). 
Patients were qualified to participate in this study, depending on the requirements defined by the study protocol.

The inclusion criteria:

1) Confirmed mild and moderate cases of COVID-19 infection (patients with oxygen saturation $>92 \%$; respiratory rate $\leq 30$ breaths/min; lung infiltrates $<$ $50 \%)$.

2) Age $\geq 18$ years old

3) Both genders were included.

4) All socioeconomic classes were included.

A verified case of COVID is determined by positive RT-PCR examination of samples from pharyngeal and nasal cavities.

Exclusion criteria:

1) Presence of mental retardation, dementia, or delirium.

2) Refusal to sign the consent.

3) Confirmed severe cases of COVID-19 infection (patients with oxygen saturation $<92 \%$; respiratory rate $\geq 30$ breaths/min; lung infiltrates $>50 \%$ ).

\section{Sampling}

Since the research is novel and no published articles were used for sample size calculation, we carried out a pilot study. The pilot study was a crucial stage in the research, and we conducted it to estimate the expected difference between home and hospital isolation. Besides, it identifies potential problems and deficiencies in the research tools and protocol before implementation during the whole study [20].

The pilot study was conducted using a small sample of 20 patients (10 home isolated and 10 hospitals isolated). This pilot study revealed that the DTS score in home isolation versus hospital isolation was $22.2 \pm 8.0$ vs 27.1 \pm 8.2 at a confidence level of $95 \%$ and $80 \%$ power. This finding was used to calculate the research sample size, which was 89 COVID-19 patients. The sample size was calculated by the OPEN EPI software package [21].

Patients in the pilot study were excluded from the original research sample due to the tool modifications and avoid inter-observer bias.

\section{Tools and operational procedures}

All participants enrolled in this study were subjected to the following (through an online Google form and phone call):

1- The online Google form that was sent to the patients to respond consisted of four sections:
The first section explained the current study's aim and procedures. It included an obligatory inquiry with a yes or no answer representing the participants' acceptance or refusal to participate in our research.

The second section included the semi-structured COVID-19 questionnaire, which contained obligatory questions to collect sociodemographic data (age, sex, marital status, education. occupation, and residence) and clinical data (having a chronic disease, smoking, personal, or family history of the psychiatric disorder), and questions that assisted some psychiatric symptoms of the subjects (mood status, having obsessive or paranoid thoughts, hallucinations, memory, and concentration).

The third and fourth section included the patients' psychometric assessments via the Arabic version of the Hospital Anxiety and Depression Scale (HADS) and the Arabic version of the Davidson Trauma Scale (DTS).

\section{The Arabic version of (HADS)}

This scale is used for screening depression and anxiety. It includes 14 questions: 7 questions for the anxiety component (HADS-Anxiety) and 7 questions for the depression component (HADS-Depression). The scores for anxiety and depression ranged from 0 to 21 points. Levels $1-7$ were considered normal, whereas $8-10$ is regarded as borderline, > 11 considered abnormal and denoted considerable symptoms of anxiety or depression. The internal consistency of the scales was $87 \%$ and $81 \%$, respectively [22]. Terkawi AS and his collaborators performed a systematic translation process to translate the original English HADS into Arabic. They documented that the Cronbach $\alpha$ for the HADS-Anxiety subscale was 0.83 (95\% confidence interval $0.79-0.88$ ) and for the HADS-Depression subscale was 0.77 (0.7$0.83)$. HADS-Anxiety score was strongly correlated with GAD-7, and HADS-Depression score was strongly associated with MDI. Besides, the results showed adequate internal consistency of HADS subscales among the patients [23]. The HADS questionnaire has been validated in many languages, countries, and settings, including general practice and community settings. HADS has been used in the HUNT study in Norway, a large community setting study done on the general population [24]. In our research, the scale showed excellent internal consistency with a Cronbach alpha coefficient of 0.84 .

The Arabic version of the Davidson Trauma Scale (DTS) This scale is used for diagnosing post-traumatic stress disorder (PTSD). The DTS is a 17 -item questionnaire that tests for PTSD symptoms. Objects are rated on a five- 
point scale $(0=$ "not at all distressing" to $4=$ "extremely distressing") to measure the degree of distress they produce. Participants are asked to define the most impactful event that has influenced them and how much trouble they are experiencing. Cut off point of 40 was used to distinguish between positive and negative cases. The testretest reliability was $r=0.86$ and internal consistency was $r=0.99[25,26]$. It was translated to Arabic by Abdul Aziz Thabet, and Sady and Badr validated it in their study with a sample of adolescent sons of martyrs in Jablah, Syria. Cronbach alpha coefficient was 0.762 [27]. In our study, the scale showed excellent internal consistency with a Cronbach alpha coefficient of 0.8 .

The HADS and DTS scales were tested for content validity by two panels of the Psychiatric Department experts. These experts assessed the tools for clarity, relevance, comprehensiveness, applicability, and understanding.

The reliability of the HADS and DTS scales was tested by measuring their internal consistency. It demonstrated an excellent level of reliability (Cronbach's alpha $=0.84$ and 0.81 ), respectively.

\section{Statistical analysis}

The statistical analysis was performed using SPSS software version 27 [28], and then the data were presented in tables. Quantitative data were introduced as mean, standard deviation, and range, whereas qualitative data were presented as frequencies and proportions. Kolmogorov-Smirnov and Levene tests were conducted to evaluate the distribution characteristics of variables and homogeneity of variance.

Pearson's chi-squared test $\left(\chi^{2)}\right.$, Fisher's exact test, and chi-square for linear trend were used to analyze qualitative variables as appropriate. Mann-Whitney (MW) $U$ test was conducted to analyze quantitative data. Binary logistic regression analysis was performed to remove confounding factors. The $P$ value of $<0.05$ was considered statistically significant.

\section{Results}

The study involved 89 patients with confirmed COVID19 virus, and the patients were divided into two groups: 43 patients in the home-isolated group (group A) and 46 patients in the hospital-isolated group (group B).

\section{Results of the sociodemographic data}

The majority of the participants in both groups were male (67.4\%) from group A and (69.6\%) from group B and were highly educated.

The mean age was $39.9 \pm 8.8$ in group $\mathrm{A}$ and $41.3 \pm$ 9.3 in group $B$.

(72.1\%) from group A and $60.9 \%$ from group B were married.
(30.2\%) from group A and 47.8\% from group B had a medical occupation (Table 1).

\section{Results of the health-related conditions}

Ten patients from the home-isolated group and 6 from the hospital-isolated group had a history of psychiatric disorder.

We found that $27.9 \%$ from the home-isolated group and 50\% from the hospital-isolated group had a chronic disease which was a statistically significant difference $p=$ 0.03 .

There was a statistically significant increase in the suicidal thoughts in the home-isolated group (37.2\%) compared to hospital-isolated group (13\%) ( $\left.p=0.008^{* * *}\right)$. (Table 1).

\section{Hospital anxiety and depression scale results}

HADS scores were calculated for all patients. The results were categorized according to the scale into three categories: normal, borderline, and abnormal Scores for depression and anxiety. The abnormal scores denote considerable symptoms of anxiety or depression (Table 2).

We found a statistically significant increase in the abnormal scores of HADS-Depression in the homeisolated group (69.7\%) compared to the hospital-isolated group (32.6\%) $\left(p<0.001^{* * *}\right)$ (Table 2).

Our results showed that $32.6 \%$ from the home-isolated group and $39.1 \%$ from the hospital-isolated group had abnormal scores of HADS-Anxiety which was statistically non-significant (Table 2).

\section{Davidson Trauma Scale results}

DTS scores were calculated for all patients. The results were categorized according to the scale into two categories: positive and negative (Table 2).

We found that $66.7 \%$ and $87.2 \%$ scored positive by the Davidson Trauma Scale (DTS) in the home-isolated group and hospital-isolated group, respectively, which was statistically significant $\left(p=0.02^{* * *}\right)$. There was a statistically significant increase $\left(p^{<} 0.001^{* * *}\right)$ in DTS scores among the hospital-isolated group with a mean score of $28.5 \pm 5.9$ compared to the home-isolated group with a mean score of $22.8 \pm 4.3$ (Table 2).

\section{Results regarding having both abnormal scores in HADS and positive results in DTS}

We found that $30.4 \%$ in the hospital-isolated group and $11.6 \%$ in the home-isolated group had both abnormal scores in HADS-Anxiety and positive results in DTS, which was statistically significant $(p=0.03 *)$. On the contrary, we found that $48.8 \%$ in the home-isolated group and $23.9 \%$ in the hospital-isolated group had both abnormal scores in HADS-Depression and positive 
Table 1 Comparison between home-isolated patients and hospital-isolated patients in demographic, clinical characteristics, and psychiatric symptoms

\begin{tabular}{|c|c|c|c|c|}
\hline Variables & & $\begin{array}{l}\text { Home isolation }(n=43) \\
\text { Group A }\end{array}$ & $\begin{array}{l}\text { Hospital isolation }(n=46) \\
\text { Group B }\end{array}$ & $p$ \\
\hline \multirow[t]{21}{*}{ Demographic characteristics } & Age (years): & & & \\
\hline & Mean \pm SD & $39.9 \pm 8.8$ & $41.3 \pm 9.3$ & 0.5 \\
\hline & Sex, $n(\%):$ & & & \\
\hline & Male & $29(67.4 \%)$ & $32(69.6 \%)$ & 0.8 \\
\hline & Female & $14(32.6 \%)$ & $14(30.4 \%)$ & \\
\hline & Marital status, $n(\%)$ : & & & \\
\hline & Married & $31(72.1 \%)$ & $28(60.9 \%)$ & 0.4 \\
\hline & Single & $5(11.6 \%)$ & $7(15.2 \%)$ & \\
\hline & Divorced & $5(11.6 \%)$ & $4(8.7 \%)$ & \\
\hline & Widow & $2(4.7 \%)$ & $7(15.2 \%)$ & \\
\hline & Education, $n(\%)$ : & & & \\
\hline & Primary and preparatory education & $4(9.3 \%)$ & $2(4.3 \%)$ & 0.8 \\
\hline & Secondary education & $6(14.0 \%)$ & $5(10.9 \%)$ & \\
\hline & High education & $23(53.4 \%)$ & $28(60.9 \%)$ & \\
\hline & Post-graduate education & $10(23.3 \%)$ & $11(23.9 \%)$ & \\
\hline & Occupation, $n$ (\%): & & & \\
\hline & Medical & $13(30.2 \%)$ & $22(47.8 \%)$ & 0.09 \\
\hline & Non-medical & $30(69.8 \%)$ & $24(52.2 \%)$ & \\
\hline & Residence, $n$ (\%): & & & \\
\hline & Urban & $19(44.2 \%)$ & $26(56.5 \%)$ & 0.2 \\
\hline & Rural & $24(55.8 \%)$ & $20(43.5 \%)$ & \\
\hline \multirow[t]{12}{*}{ Clinical characteristics } & Chronic disease, $n$ (\%): & $12(27.9 \%)$ & $23(50.0 \%)$ & $0.03^{* *}$ \\
\hline & Smoking, $n$ (\%): & $10(23.3 \%)$ & $17(37.0 \%)$ & 0.2 \\
\hline & History of psychiatric disorder, $n(\%):$ & & & \\
\hline & Depression & $5(11.6 \%)$ & $3(6.5 \%)$ & 0.5 \\
\hline & Insomnia & $2(4.7 \%)$ & $1(2.2 \%)$ & \\
\hline & Anxiety & $3(7.0 \%)$ & $1(2.2 \%)$ & \\
\hline & OCD & $0(0.0 \%)$ & $1(2.2 \%)$ & \\
\hline & Family history of psychiatric disorder, $n$ (\%): & & & \\
\hline & Depression & $5(11.6 \%)$ & $7(15.2 \%)$ & 0.7 \\
\hline & $\mathrm{OCD}$ & $3(7.0 \%)$ & $4(8.7 \%)$ & \\
\hline & Insomnia & $3(7.0 \%)$ & $1(2.2 \%)$ & \\
\hline & Bipolar disorder & $2(4.7 \%)$ & $2(4.3 \%)$ & \\
\hline \multirow[t]{9}{*}{ Psychiatric symptoms } & Mood status: & & & \\
\hline & Positive (relaxed, calm, cheerful) & $5(15.6 \%)$ & $11(23.9 \%)$ & 0.4 \\
\hline & Negative (nervous, irritated, sad) & $27(84.4 \%)$ & $35(76.1 \%)$ & \\
\hline & Loss of concentration & $42(97.7 \%)$ & $40(87.0 \%)$ & 0.1 \\
\hline & Weakness of memory & $39(90.7 \%)$ & $37(80.4 \%)$ & 0.2 \\
\hline & Annoying, urgent, and repetitive thoughts & 17 (39.5\%) & 11 (23.9\%) & 0.1 \\
\hline & Paranoid thoughts & $5(11.6 \%)$ & $9(19.6 \%)$ & 0.3 \\
\hline & Suicide thoughts & $16(37.2 \%)$ & $6(13.0 \%)$ & $0.008^{* *}$ \\
\hline & Hallucinations & $0(0.0 \%)$ & $3(6.5 \%)$ & 0.2 \\
\hline
\end{tabular}

Test of significance: Pearson's chi-squared test, Fisher's exact test, and Student's $t$ test 
Table 2 Comparison between home-isolated patients and hospital-isolated patients in HADS and DTS and dual diagnosis

\begin{tabular}{|c|c|c|c|c|}
\hline & Variables & $\begin{array}{l}\text { Home isolation }(n=43) \\
\text { Group A }\end{array}$ & $\begin{array}{l}\text { Hospital isolation }(n=46) \\
\text { Group B }\end{array}$ & $p$ \\
\hline \multirow[t]{14}{*}{ HADS and DTS } & \multicolumn{4}{|l|}{ HADS-Anxiety: } \\
\hline & Mean \pm SD & $8.6 \pm 2.4$ & $9.3 \pm 2.2$ & \multirow[t]{2}{*}{0.1} \\
\hline & - Normal (0-7) & 19 (44.2\%) & $17(37.0 \%)$ & \\
\hline & • Borderline (8-10) & $10(23.3 \%)$ & $11(23.9 \%)$ & \multirow[t]{2}{*}{0.3} \\
\hline & - Abnormal (11-21) & $14(32.6 \%)$ & 18 (39.1\%) & \\
\hline & \multicolumn{4}{|l|}{ HADS-Depression: } \\
\hline & Mean \pm SD & $12.2 \pm 3.6$ & $9.8 \pm 2.7$ & \multirow[t]{2}{*}{$<0.001 * *$} \\
\hline & • Normal (0-7) & $6(14.0 \%)$ & $13(28.3 \%)$ & \\
\hline & - Borderline (8-10) & $7(16.3 \%)$ & $18(39.1 \%)$ & \multirow[t]{2}{*}{$0.003^{* *}$} \\
\hline & • Abnormal (11-21) & $30(69.7 \%)$ & 15 (32.6\%) & \\
\hline & \multicolumn{4}{|l|}{ Davidson Trauma Scale: } \\
\hline & Mean \pm SD & $22.8 \pm 4.3$ & $28.5 \pm 5.9$ & \multirow[t]{2}{*}{$<0.001 * *$} \\
\hline & • Positive DTS ( $\geq 35$ ) & $28(66.7 \%)$ & 41 (87.2\%) & \\
\hline & • Negative DTS (`35) & $14(33.3 \%)$ & $6(12.8 \%)$ & $0.02^{* *}$ \\
\hline \multirow{9}{*}{$\begin{array}{l}\text { Having both abnormal scores in HADS } \\
\text { and positive results in DTS }\end{array}$} & \multicolumn{4}{|c|}{ Abnormal scores in HADS-Anxiety and positive results in DTS: } \\
\hline & Present & $5(11.6 \%)$ & $14(30.4 \%)$ & \multirow[t]{2}{*}{$0.03^{* *}$} \\
\hline & Absent & $38(88.4 \%)$ & $32(69.6 \%)$ & \\
\hline & \multicolumn{4}{|c|}{ Abnormal scores in HADS-Depression and positive results in DTS: } \\
\hline & Present & $21(48.8 \%)$ & $11(23.9 \%)$ & \multirow[t]{2}{*}{$0.01 * *$} \\
\hline & Absent & $22(51.2 \%)$ & $35(76.1 \%)$ & \\
\hline & \multicolumn{4}{|c|}{ Abnormal scores in both HADS-Depression and HADS-Anxiety: } \\
\hline & Present & $9(20.9 \%)$ & $4(8.7 \%)$ & \multirow[t]{2}{*}{0.1} \\
\hline & Absent & $34(79.1 \%)$ & $42(91.3 \%)$ & \\
\hline
\end{tabular}

Test of significance: Student's $t$ test and chi-square for linear trend

${ }^{*}$ Statistical significance

results in DTS, which was statistically significant $(p=$ $0.01 *$ ) (Table 2).

Results regarding the association between HADS-Anxiety and demographic and clinical characteristics of the studied patients

Our result showed a statistically significant association between having abnormal HADS-Anxiety scores and [the female sex $\left(p<0.001^{* * *}\right)$ lower education levels $(p=$ $0.02 * *)$, non-medical occupation $(p<0.001 \%)$, and the presence of a family history of psychiatric disorder $(p=$ $\left.0.002^{* *}\right)$ ] (Table 3).

Results regarding the association between HADSDepression and demographic and clinical characteristics of the studied patients

Our results showed a statistically significant association between having abnormal HADS-Depression scores and [the female sex $\left(p=0.01^{* * *}\right)$ non-medical occupation $(p<$ $\left.0.001^{* *}\right)$, and the presence of a family history of psychiatric disorder $\left(p=0.003^{* * *}\right)$ ] (Table 4$)$.
Results regarding the association between the Davidson Trauma Scale and demographic and clinical characteristics of the studied patients

Our results revealed a statistically significant association between positive DTS scores and (the female sex $(p=$ $0.01 \%)$, lower education levels $(p<0.001 \%$ ), and nonmedical occupations $\left(p=0.01^{* * *)}\right)$ (Table 5)

Results of the binary logistic regression analysis of HADS scores and DTS scores with significantly related independent factors

The binary logistic regression analysis of HADS and DTS with significantly related independent factors revealed a significant model for predicting HADS and DTS scores (Table 6).

Lower education levels (primary, preparatory, and secondary) and family history of psychiatric disorder were found to be risk factors for having abnormal HADSAnxiety scores in COVID-19 patients [OR 95\% CI 4.5 (1.9-19.2) and 2.2 (1.07-17.3), respectively] (Table 6).

The medical occupation was a protective factor against having abnormal HADS-Depression scores in COVID- 
Table 3 Association between HADS-Anxiety and demographic and clinical characteristics of the studied patients

\begin{tabular}{|c|c|c|c|c|c|c|c|}
\hline \multirow[t]{2}{*}{ Demographic and clinical characteristics } & \multicolumn{2}{|c|}{ Normal } & \multicolumn{2}{|c|}{ Borderline } & \multicolumn{2}{|c|}{ Abnormal } & \multirow[t]{2}{*}{$P$} \\
\hline & No. & $\%$ & No. & $\%$ & No. & $\%$ & \\
\hline \multicolumn{8}{|l|}{ Age: } \\
\hline 40 years old $(n=44)$ & 23 & 52.3 & 8 & 18.2 & 13 & 29.5 & \multirow[t]{2}{*}{0.07} \\
\hline$\geq 40$ years old $(n=45)$ & 13 & 28.9 & 13 & 28.9 & 19 & 42.2 & \\
\hline \multicolumn{8}{|l|}{ Sex: } \\
\hline Male $(n=61)$ & 35 & 57.4 & 7 & 11.5 & 19 & 31.1 & \multirow[t]{2}{*}{$<0.001^{* *}$} \\
\hline Female $(n=28)$ & 1 & 3.6 & 14 & 50.0 & 13 & 46.4 & \\
\hline \multicolumn{8}{|l|}{ Marital status: } \\
\hline Married $(n=59)$ & 28 & 47.5 & 10 & 16.9 & 21 & 35.6 & \multirow[t]{2}{*}{0.06} \\
\hline Single/divorced/widow $(n=30)$ & 8 & 62.5 & 11 & 0.0 & 11 & 37.5 & \\
\hline \multicolumn{8}{|l|}{ Education level: } \\
\hline Primary, preparatory, and secondary education $(n=17)$ & 4 & 23.5 & 2 & 11.8 & 11 & 64.7 & \multirow[t]{2}{*}{$0.02^{* *}$} \\
\hline High- and post-graduate education $(n=72)$ & 32 & 44.4 & 19 & 26.4 & 21 & 29.2 & \\
\hline \multicolumn{8}{|l|}{ Occupation: } \\
\hline Medical $(n=35)$ & 23 & 65.7 & 3 & 8.6 & 9 & 25.7 & \multirow[t]{2}{*}{$<0.001^{* *}$} \\
\hline Non-medical $(n=54)$ & 13 & 24.1 & 18 & 33.3 & 23 & 41.6 & \\
\hline \multicolumn{8}{|l|}{ Residence: } \\
\hline Urban $(n=45)$ & 20 & 44.4 & 7 & 15.6 & 18 & 40.0 & \multirow[t]{2}{*}{0.2} \\
\hline Rural $(n=44)$ & 16 & 36.4 & 14 & 31.8 & 14 & 31.8 & \\
\hline Chronic disease $(n=35)$ & 14 & 40.0 & 5 & 14.3 & 16 & 45.7 & 0.2 \\
\hline Smoking $(n=27)$ & 14 & 51.9 & 3 & 11.1 & 10 & 37.0 & 0.1 \\
\hline History of psychiatric disorder $(n=16)$ & 5 & 31.3 & 2 & 12.5 & 9 & 56.2 & 0.2 \\
\hline Family history of psychiatric disorder $(n=27)$ : & 6 & 22.2 & 4 & 14.8 & 17 & 63.0 & $0.002^{* *}$ \\
\hline
\end{tabular}

Test of significance: chi-square for linear trend

**Statistical significance

19 patients [OR 95\% 0.24 (0.11-0.74)], while home isolation was a risk factor [OR 95\% 1.5 (1.1-20.9)] (Table 6).

On the contrary, the medical occupation was a risk factor for scoring positive in DTS in COVID-19 patients [OR 95\% 5.2 (1.9-27.8)] while low levels of education (primary, preparatory, and secondary) and home isolation were protective factors [OR 95\% CI 0.13 (0.04-0.69) and $0.17(0.08-0.84)$, respectively] (Table 6).

\section{Discussion}

A worldwide public health crisis was announced on 30 January 2020, by the World Health Organization, which then formally recognized the SARS-CoV-2 epidemic as a pandemic [29].. On 19 June 2020, the WHO documented more than 80 million SARS-CoV-2 patients from impacted nations [30]. Scientists tend to link COVID-19 to various psychiatric problems in many populations, including the infected people and the physicians who treat them [31, 32]. This would be daunting for doctors; consequently, psychological and social services are essential to alleviate physical and mental health issues in the medical community [33, 34].
Few papers investigate the psychological impact of COVID-19 on infected patients; nonetheless, none of them has demonstrated the effect of isolation on these patients. Our study is the first in Egypt to determine the psychiatric problems in home-isolated and hospital-isolated patients suffering from COVID19 and compare them. The current research showed that most patients had initial responses of anxiety, fear, and sadness with a more negative attitude about their prognosis, with most believing that their illness will affect their future. Negative emotional responses to the disease can be illustrated by the prevalent reported data on the disease and the rapidly increasing number of deaths caused by it. Some patients [19] experienced thoughts of suicide after being infected, which was clinically more prevalent in patients in home isolation than hospital isolation (six patients).

Due to challenges caused by the pandemic, such as economic hardship, social alienation, decreased access to public medical and mental health services, and the stigma caused by infection with COVID-19, suicide rates could be elevated among home-isolated patients [35, 36]. 
Table 4 Association between HADS-Depression and demographic and clinical characteristics of the studied patients

\begin{tabular}{|c|c|c|c|c|c|c|c|}
\hline \multirow[t]{2}{*}{ Demographic and clinical characteristics } & \multicolumn{2}{|c|}{ Normal } & \multicolumn{2}{|c|}{ Borderline } & \multicolumn{2}{|c|}{ Abnormal } & \multirow[t]{2}{*}{$P$} \\
\hline & No. & $\%$ & No. & $\%$ & No. & $\%$ & \\
\hline \multicolumn{8}{|l|}{ Age: } \\
\hline 40 years old $(n=44)$ & 13 & 29.5 & 11 & 25.0 & 20 & 45.5 & \multirow[t]{2}{*}{0.1} \\
\hline$\geq 40$ years old $(n=45)$ & 6 & 13.3 & 14 & 31.1 & 25 & 55.6 & \\
\hline \multicolumn{8}{|l|}{ Sex: } \\
\hline Male $(n=61)$ & 18 & 29.5 & 14 & 23.0 & 29 & 47.5 & \multirow[t]{2}{*}{$0.01^{* *}$} \\
\hline Female $(n=28)$ & 1 & 3.6 & 11 & 39.3 & 16 & 57.1 & \\
\hline \multicolumn{8}{|l|}{ Marital status: } \\
\hline Married $(n=59)$ & 17 & 28.8 & 15 & 25.4 & 27 & 45.8 & \multirow[t]{2}{*}{0.06} \\
\hline Single/divorced/widow $(n=30)$ & 2 & 6.7 & 10 & 33.3 & 18 & 60.0 & \\
\hline \multicolumn{8}{|l|}{ Education level: } \\
\hline Primary, preparatory, and secondary education $(n=17)$ & 4 & 23.5 & 2 & 11.8 & 11 & 64.7 & \multirow[t]{2}{*}{0.2} \\
\hline High- and post-graduate education $(n=72)$ & 15 & 20.8 & 23 & 31.9 & 34 & 47.2 & \\
\hline \multicolumn{8}{|l|}{ Occupation: } \\
\hline Medical $(n=35)$ & 14 & 40.0 & 7 & 20.0 & 14 & 40.0 & \multirow[t]{2}{*}{$<0.001^{* *}$} \\
\hline Non-medical $(n=54)$ & 5 & 9.3 & 18 & 33.3 & 31 & 60.9 & \\
\hline \multicolumn{8}{|l|}{ Residence: } \\
\hline Urban $(n=45)$ & 13 & 28.9 & 11 & 24.4 & 21 & 46.7 & \multirow[t]{2}{*}{0.2} \\
\hline Rural $(n=44)$ & 6 & 13.6 & 14 & 31.8 & 24 & 54.5 & \\
\hline Chronic disease $(n=35)$ & 12 & 34.2 & 8 & 22.9 & 15 & 42.9 & 0.6 \\
\hline Smoking $(n=27)$ & 9 & 33.3 & 7 & 25.9 & 11 & 40.7 & 0.1 \\
\hline History of psychiatric disorder $(n=16)$ & 5 & 31.3 & 5 & 31.3 & 6 & 37.4 & 0.4 \\
\hline Family history of psychiatric disorder $(n=27)$ & 8 & 29.6 & 1 & 3.7 & 18 & 66.7 & $0.003^{* *}$ \\
\hline
\end{tabular}

Test of significance: chi-square for linear trend

**Statistical significance

Our results reported a statistically significant increase in the abnormal scores of HADS-Depression in the home-isolated group (69.7\%) compared to the hospitalisolated group (32.6\%). Moreover, we detected that $32.6 \%$ from group A and 39.1\% from group B had abnormal scores of HADS-Anxiety, which means that the patients had considerable symptoms of anxiety or depression. We found $66.7 \%$ and $87.2 \%$ scored positive by the Davidson Trauma Scale (DTS) in the homeisolated group and group B, respectively, indicating the presence of post-traumatic stress symptoms.

Zhang, J and his colleagues documented a study-sized sample of 144 cases, in which they found severe anxiety (34\%) and depression (28\%) for patients admitted to isolation wards. Whereas other research included 26 patients, it found higher anxiety and depressive symptoms in hospital admitted patients. The third study that recruited 57 patients with COVID-19 observed that depression in recently cured (COVID-19) patients were $30 \%$ [37]. A significant sample size study $(n=714)$ of hospitalized COVID-19 patients found post-traumatic stress symptoms in $96.2 \%$ of them [6].
In a recently released meta-analysis and systematic review that incorporated 1963 studies and 87 preprints, the number of coronavirus cases was about 3559 from different countries. In contrast, there were 47 studies of SARS-CoV involving 2068 subjects, 13 studies involving MERS-CoV, and 12 reviews documenting SARS-CoV-2 (976 cases). During acute illness, the most frequent symptoms of patients diagnosed with SARS or MERS were confusion (27.9\%), depression (32.6\%), anxiety (35.7\%), and poor memory (34.1\%). By comparing the data obtained on COVID-19 patients, there was evidence of dementia (confusion 65\%). After discharge from the hospital, 33\% of assessed COVID-19 met the requirements for the dysexecutive syndrome [38].

Pathology of different symptoms can be distinct due to inflammation, as some studies indicate that the central nervous system may be affected by COVID-19, increasing the inflammatory immune response. In subjects with COVID-19, there is an elevation in serum C-reactive protein and high levels of pro-inflammatory cytokines and decreased total blood lymphocyte counts [38]. Neurotropic SARS-CoV-2 infection hypoxia, 
Table 5 Association between the Davidson Trauma Scale and demographic and clinical characteristics of the studied patients

\begin{tabular}{|c|c|c|c|c|c|}
\hline \multirow[t]{2}{*}{ Demographic and clinical characteristics } & \multicolumn{2}{|c|}{ Positive DTS } & \multicolumn{2}{|c|}{ Negative DTS } & \multirow[t]{2}{*}{$P$} \\
\hline & No. & $\%$ & No. & $\%$ & \\
\hline \multicolumn{6}{|l|}{ Age: } \\
\hline 40 years old $(n=44)$ & 35 & 79.6 & 9 & 20.4 & \multirow[t]{2}{*}{0.7} \\
\hline$\geq 40$ years old $(n=45)$ & 34 & 75.6 & 10 & 24.4 & \\
\hline \multicolumn{6}{|l|}{ Sex: } \\
\hline Male $(n=61)$ & 52 & 85.3 & 9 & 14.7 & \multirow[t]{2}{*}{$0.01^{* *}$} \\
\hline Female $(n=28)$ & 17 & 60.7 & 11 & 39.3 & \\
\hline \multicolumn{6}{|l|}{ Marital status: } \\
\hline Married $(n=59)$ & 49 & 83.1 & 10 & 16.9 & \multirow[t]{2}{*}{0.08} \\
\hline Single/divorced/widow $(n=30)$ & 20 & 66.7 & 6 & 33.3 & \\
\hline \multicolumn{6}{|l|}{ Education level: } \\
\hline Primary, preparatory, and secondary education $(n=17)$ & 8 & 47.1 & 9 & 52.9 & \multirow[t]{2}{*}{$<0.001^{* *}$} \\
\hline High- and post-graduate education $(n=72)$ & 61 & 84.7 & 11 & 15.3 & \\
\hline \multicolumn{6}{|l|}{ Occupation: } \\
\hline Medical $(n=35)$ & 32 & 91.4 & 3 & 8.6 & \multirow[t]{2}{*}{$0.01 * *$} \\
\hline Non-medical $(n=54)$ & 37 & 68.5 & 17 & 31.5 & \\
\hline \multicolumn{6}{|l|}{ Residence: } \\
\hline Urban $(n=45)$ & 35 & 77.8 & 10 & 22.2 & \multirow[t]{2}{*}{0.9} \\
\hline Rural $(n=44)$ & 34 & 77.3 & 10 & 22.7 & \\
\hline Chronic disease $(n=35)$ & 24 & 68.6 & 11 & 31.4 & 0.1 \\
\hline Smoking $(n=27)$ & 20 & 74.1 & 7 & 25.9 & 0.6 \\
\hline History of psychiatric disorder $(n=16)$ & 11 & 68.8 & 5 & 31.2 & 0.4 \\
\hline Family history of psychiatric disorder $(n=27)$ & 19 & 70.4 & 8 & 29.6 & 0.3 \\
\hline
\end{tabular}

Test of significance: Pearson's chi-square test

* Statistical significance

Table 6 Binary logistic regression analysis of HADS scores and DTS scores with significantly related independent factors

\begin{tabular}{|c|c|c|c|c|}
\hline Variables & S.E. & Wald & Sig. & Odds ratio $(95 \% \mathrm{Cl})$ \\
\hline \multicolumn{5}{|l|}{ HADS-Anxiety (abnormal scores): } \\
\hline - Male sex & 0.81 & 0.08 & 0.6 & $0.97(0.71-2.2)$ \\
\hline - Primary, preparatory, and secondary education (RF) & 0.62 & 6.4 & $0.01^{* *}$ & $4.5(1.9-19.2)$ \\
\hline - Medical occupation & 0.66 & 2.6 & 0.1 & $0.27(0.11-1.9)$ \\
\hline - Family history of psychiatric disorder (RF) & 0.61 & 5.0 & $0.02^{* *}$ & $2.2(1.07-17.3)$ \\
\hline \multicolumn{5}{|l|}{ HADS-Depression (abnormal scores): } \\
\hline - Male sex & 0.61 & 1.8 & 0.7 & $0.67(0.45-1.8)$ \\
\hline - Medical occupation (PF) & 0.52 & 7.4 & $0.03^{* *}$ & $0.24(0.11-0.74)$ \\
\hline - Family history of psychiatric disorder & 0.64 & 2.4 & 0.1 & $0.47(0.12-2.1)$ \\
\hline - Home isolation (RF) & 0.51 & 7.8 & $0.02^{* *}$ & $1.5(1.1-20.9)$ \\
\hline \multicolumn{5}{|l|}{ DTS (positive): } \\
\hline - Male sex & 0.54 & 1.0 & 0.1 & $1.2(0.64-6.2)$ \\
\hline - Primary, preparatory, and secondary education (PF) & 0.64 & 6.7 & $0.01^{* *}$ & $0.13(0.04-0.69)$ \\
\hline - Medical occupation (RF) & 0.76 & 5.4 & $0.02^{* *}$ & $5.2(1.9-27.8)$ \\
\hline • Home isolation (PF) & 0.66 & 6.7 & $0.01^{* *}$ & $0.17(0.08-0.84)$ \\
\hline
\end{tabular}

$R F$ risk factors (odds ratio $>1$ )

$P F$ protective factors (odds ratio $<1$ )

**Statistical significance 
cerebrovascular events, and steroid therapy have impact on neurological status. These various biological mechanisms have been proposed to function as mediators of psychological impairment in COVID-19; however, there is insufficient evidence [39]. Similarly, like other physical disorders, social influences can directly intensify the psychiatric effects of exposure to COVID-19. Moreover, quarantine procedures can contribute to insomnia and psychological distress [40].

The current findings regarding the impact of the isolation setting type on presenting the patients' psychiatric symptoms can be illustrated from various perspectives. First, hospitalized patients may have elevated posttraumatic stress levels related to the transition to a new environment. Since the human and physical hospital setting is often psychologically unhealthy, it can be loud, sensory-deprived, and disorienting. These environmental factors inhibit mobility, intensify disorientation, disturb sleep, and lead to social isolation, in addition to anxiety and apprehension. Furthermore, the deterioration of the physical condition, along with the inability to communicate with their family, fear of mortality, knowledge of the medical status of relatives and colleagues, as well as knowledge of other infected patients who died or were admitted to ICU $[38,39]$ can lead to increased posttraumatic symptoms in these patients. Isolation at home makes patients feel relaxed and safe with their familiar social surroundings; however, other factors may lead to adverse psychological effects, including the emergence of instantaneous stigma as a significant defect of infection due to individuals' discrimination quarantine. This stigma may be prevalent when isolated at home and shunned by local neighbors, besides being afraid of transmitting the disease to their relatives and fear of sudden complications without receiving instant medical aid while in home isolation.

Moreover, after being discharged from the hospital, several patients treated for COVID-19 reported discrimination [40].

We found that the medical occupation has a protective effect against having abnormal HADS-Depression scores in COVID-19 patients; nevertheless, it increases the risk of having positive scores in the DTS. Some literature investigated the psychological harm caused by pandemics to medical staff who suffered from psychiatric symptoms like anxiety, depression, terror, and trauma. They reported that multiple factors, including having respiratory or digestive symptoms, negative coping style, and job burnout, participate in the anxiety or depression of healthcare workers [41]. We found that lower education levels (primary, preparatory, and secondary) were found to be risk factors for having abnormal HADS-Anxiety scores in COVID-19 patients. That was consistent with the study of Bjelland and his collaborates who found that low educational levels were significantly associated with both anxiety and depression [42].

The limitations of the current analysis must be considered when analyzing the results, which involve a limited sample size. Participants of the current research had mild to moderate cases of COVID-19 infection, in addition to the lack of appropriate reference groups to compare them with the current participants. Finally, we did not include quantitative biochemical tests, such as blood markers, to measure the inflammatory immune response.

\section{Conclusion}

We conclude that a significant number of patients diagnosed with the COVID-19 disease develop depressive, anxiety, and post-traumatic stress symptoms, whether they were isolated in the hospital or at home; besides, the isolation setting may affect the presenting symptoms.

\section{Abbreviations}

$\mathrm{CT}$ : Computed tomography; SARS-CoV-2: Severe acute respiratory syndrome coronavirus 2; DTS: Davidson Trauma Scale; HADS: Hospital Anxiety and Depression Scale; MW: Mann-Whitney $U$ test; PTSD: Post-traumatic stress disorder; RT-PCR: Reverse transcription-polymerase chain reaction; $X^{2}$ : Chisquare test

\section{Acknowledgements}

The authors would like to show their gratitude to all the study participants.

\section{Authors' contributions}

AY designed the work acquisition and shared in the drafting of the article, and substantively revised it. AE contributed to the interpretation of data and shared in the acquisition of data and the drafting of the article. AY and AE wrote the final manuscript, and AE submitted it for publication. All authors agreed with the results and conclusions of this research and approved the final manuscript.

\section{Funding}

No funding or support was received.

Availability of data and materials

The researchers can clarify all the data when needed.

\section{Declarations}

Ethics approval and consent to participate

- At the Faculty of Medicine, the Institutional Review Board accepted this study, Zagazig University, with Official permission (ZU-IRB\#6585).

- We obtained an informed electronic consent (by applying a mandatory yes or no question at the beginning of the Google form questionnaire through which we get our data due to the quarantine issue) from the subjects who participated in the study after presenting the research goals, how we would conduct the research, and how long would continue.

- Study participants could withdraw from participation without being adversely affected by their participation.

- The researchers could use this research for scientific publication, but the participants' identities will not be clarified.

Consent for publication

Not applicable.

Competing interests

The authors declare that they have no competing interests. 


\section{Received: 10 February 2021 Accepted: 3 April 2021}

\section{Published online: 04 May 2021}

\section{References}

1. Dubé B, Benton T, Cruess DG, Evans DL (2005) Neuropsychiatric manifestations of HIV infection and AIDS. J Psychiatry Neurosci 30:237-246 [PMC free article] [PubMed] [Google Scholar] [Ref list]

2. WHO 2019 novel coronavirus (2019nCoV): strategic preparedness and response plan. Feb 3, 2020. https://www.who.int/docs/default-source/ coronaviruse/srp 0402202 pdf?sfvrsn=7ff55ec0_4\&download=true [Ref list]

3. Xiang YT, Yang Y, Li W, Zhang L, Zhang Q, Cheung T, Ng CH (2020) Timely mental health care for the 2019 novel coronavirus outbreak is urgently needed. Lancet Psychiatry 7(3):228-229. https://doi.org/10.1016/S2215-03 66(20)30046-8

4. Arden MA, Chilcot J (2020) Health psychology and the coronavirus (COVID-19) global pandemic: a call for research. Br J Health Psychol 25(2):231232. https://doi.org/10.1111/bjhp.12414

5. Cullen W, Gulati G, Kelly BD (2020) Mental health in the Covid-19 pandemic. QJM 113(5):311-312. https://doi.org/10.1093/qjmed/hcaa110

6. Bo HX, Li W, Yang Y, Wang Y, Zhang Q, Cheung T, Wu X, Xiang YT (2020) Post-traumatic stress symptoms and attitude toward crisis mental health services among clinically stable patients with COVID-19 in China. Psychol Med:1-2. Advance online publication. https://doi.org/10.1017/S003329172 0000999

7. Monson E, Caron J, McCloskey K, Brunet A (2017) Longitudinal analysis of quality of life across the trauma spectrum. Psychol Trauma 9(5):605-612. https://doi.org/10.1037/tra0000254

8. Asmundson GJG, Taylor S (2020) Coronaphobia: fear and the 2019-nCov outbreak. J Anxiety Dis -Ord 70:102196. https://doi.org/10.1016/j.janxdis.202 0.102196

9. Ahmadi K, Ramezani MA (2020) Iranian emotional experience and expression during the COVID-19 Crisis. Asia Pac J Public Health 32:285-286. https://doi.org/10.1177/1010539520937097 PubMed Abstract | CrossRef Full Text | Google Scholar

10. Ahorsu DK, Lin CY, Imani V, Saffari M, Griffiths MD, Pakpour AH (2020) The fear of COVID-19 scale: development and initial validation. Int J Ment Health Addict. https://doi.org/10.1007/s11469-020-00270-8

11. Mamun MA, Griffiths MD (2020) First COVID-19 suicide case in Bangladesh due to fear of COVID-19 and xenophobia: possible suicide prevention strategies. Asian J Psychiatr 51:102073. https://doi.org/10.1016/j.ajp.2020.102 073 PubMed Abstract | CrossRef Full Text | Google Scholar'

12. Maunder RG (2009) Was SARS a mental health catastrophe? Gen Hosp Psychiatry 31:316-317. https://doi.org/10.1016/j.genhosppsych.2009.04.004 [PMC free article] [PubMed] [CrossRef] [Google Scholar]

13. Curtin NM, Boyle NT, Mills KH, Connor TJ (2009) Psychological stress suppresses innate IFN-gamma production via glucocorticoid receptor activation: reversal by the anxiolytic chlordiazepoxide. Brain Behav Immun 23(4):535-547. https://doi.org/10.1016/j.bbi.2009.02.003 [PubMed]

14. Herman JP et al (2016) Regulation of the hypothalamic-pituitaryadrenocortical stress response. Compr Physiol 6:603-621. https://doi.org/1 0.1002/cphy.c150015 [PMC free article] [PubMed] [CrossRef] [Google Scholar]

15. Ding Y, Dai J (2019) Advance in stress for depressive disorder. Adv Exp Med Biol 1180:147-178. https://doi.org/10.1007/978-981-32-9271-0_8 [PubMed] [CrossRef] [Google Scholar]

16. Prasad A, Chaichi A, Kelley D, Francis J, Gartia MR (2019) Current and future functional imaging techniques for post-traumatic stress disorder RSC. Advances. 9(42):24568-24594. https://doi.org/10.1039/c9ra03562a

17. Clark IA, Vissel B (2017) The meteorology of cytokine storms, and the clinical usefulness of this knowledge. Semin Immunopathol 39(5):505-516. https:// doi.org/10.1007/s00281-017-0628-y [PMC free article] [PubMed] [CrossRef] [Google Scholar]

18. Debnath M, Berk M, Maes M (2020) Changing dynamics of psychoneuroimmunology during the COVID-19 pandemic. Brain, Behav Immun Health 5:100096. https://doi.org/10.1016/j.bbih.2020.100096 ISSN 2666-3546. [PMC free article] [PubMed] [CrossRef] [Google Scholar]

19. Wu Y, Xu X, Chen Z, Duan J, Hashimoto K, Yang L, Liu C, Yang C (2020) Nervous system involvement after infection with COVID-19 and other coronaviruses. Brain Behav Immun. https://doi.org/10.1016/j.bbi.2020.03.031 [PMC free article] [PubMed] [CrossRef] [Google Scholar]
20. Hassan ZA, Schattner P, Mazza D (2006) Doing a pilot study: why is it essential? Malaysian family physician 1(2-3):70-73

21. Dean, A., Sullivan, K., \& Soe, M. (2013). OpenEpi: Open Source Epidemiologic Statistics for Public Health. Updated 2013/4/6. https://www.OpenEpi.com

22. Bjelland I, Dahl AA, Haug TT, Neckelmann D (2002) The validity of the hospital anxiety and depression scale-an updated literature review. J Psychosom Res 52:69-78. https://doi.org/10.1016/S0022-3999(01)00296-3 [PubMed] [CrossRef] [Google Scholar]

23. Terkawi AS, Tsang S, AlKahtani GJ, al-Mousa SH, al Musaed S, AlZoraigi US, Alasfar EM, Doais KS, Abdulrahman A, Altirkawi KA (2017) development and validation of Arabic version of the Hospital Anxiety and Depression Scale. Saudi J Anaesth 11(Suppl 1):S11-S18. https://doi.org/10.4103/sja.SJA_43_17

24. Mykletun A, Stordal E, Dahl AA (2001) Hospital anxiety and depression $(\mathrm{HAD})$ scale: Factor structure, item analyses and internal consistency in a large population. Br J Psychiatry 179:540-544 Google Scholar

25. Davidson JRT, Book SW, Colket JT, Tupler LA, Roth S, David D et al (1997) Assessment of a new self-rating scale for post-traumatic stress disorder. Psychol Med 27:153-160 [PubMed] [Google Scholar]

26. Arab Corporation for Psychological Tests. Arabic version of Davidson PTSD Scale according to DSM-IV. 2010. Available from: http://arabtesting.com/ : Personal communication with Dr. Abdel-Mawggod Abdel samiee head manager of Arab corporation for psychological test.

27. Sady R, Badr E (2015) The level of post-traumatic stress disorder (PTSD). Field Study on a sample of the sons martyrs in adolescence in area of Jablah. Tishreen Univ J Res Sci Stud- Arts Humanit Ser 37(5):265-280

28. IBM (2020) IBM SPSS Statistics for Windows, Version 27. IBM Corp, Armonk http://www-01.ibm.com/support/docview.wss?uid=swg27049428

29. WHO (2020) Novel Coronavirus (2019-nCoV). https://www.who.int/docs/defa ult-source/coronaviruse/situation-reports/20200130-sitrep-10-ncov.pdf.

30. COVID-19 Situation Update Worldwide, as of June 19 2020. https://www. ecdc.europa.eu/en/geographical-distribution-2019-ncov-cases

31. Lai J, Ma S, Wang Y, Cai Z, Hu J, Wei N, Wu J, du H, Chen T, Li R, Tan H, Kang L, Yao L, Huang M, Wang H, Wang G, Liu Z, Hu S (2020) Factors associated with mental health outcomes among health care workers exposed to coronavirus disease 2019. JAMA Netw Open 3(3):e203976. https://doi.org/10.1001/jamanetworkopen.2020.3976

32. Xiang YT, Jin Y, Cheung T (2020) Joint International Collaboration to Combat Mental Health Challenges During the Coronavirus Disease 2019 Pandemic. JAMA Psychiat 77(10):989-990. https://doi.org/10.1001/jama psychiatry.2020.1057

33. Pfefferbaum B, North CS (2020) Mental health and the Covid-19 pandemic. N Engl J Med 383(6):510-512. https://doi.org/10.1056/NEJMp2008017

34. Zhou J, Liu L, Xue P, Yang X, Tang X (2020) Mental health response to the COVID-19 outbreak in China. Am J Psychiatry 177(7):574-575. https://doi. org/10.1176/appi.ajp.2020.20030304

35. Kong X, Zheng K, Tang M (2020) Prevalence and factors associated with depression and anxiety of hospitalized patients with COVID-19. medRxiv. https://doi.org/10.1101/2020.03.24.20043075 (preprint) [CrossRef] [Google Scholar]

36. Yang L, Wu D, Hou Y (2020) Analysis of psychological state and clinical psychological intervention model of patients with COVID-19. medRxiv. https:// doi.org/10.1101/2020.03.22.20040899 (preprint) [CrossRef] [Google Scholar]

37. Zhang J, Lu H, Zeng H, Zhang S, Du Q, Jiang T, Du B (2020) The differential psychological distress of populations affected by the COVID-19 pandemic. Brain Behav Immun 87:49-50. https://doi.org/10.1016/j.bbi.2020.04.031

38. Rogers JP, Chesney E, Oliver D et al (2020) Psychiatric and neuropsychiatric presentations associated with severe coronavirus infections: a systematic review and meta-analysis with comparison to the COVID-19 pandemic. Lancet Psychiatry 7(7):611-627. https://doi.org/10.1016/S2215-0366(20)302 03-0pmid: http://www.ncbi.n/m.nih.gov/pubmed/32437679

39. Brooks SK, Webster RK, Smith LE, Woodland L, Wessely S, Greenberg N, Rubin GJ (2020) The psychological impact of quarantine and how to reduce it: rapid review of the evidence. Lancet 395(10227):912-920. https://doi. org/10.1016/S0140-6736(20)30460-8

40. imes of India. Times India; 2020. Recovered coronavirus patients face social stigma in Bihar | Patna News - Times of India [WWW Document] URL https://timesofindia.indiatimes.com/city/patna/recovered-corona-patients-fa ce-social-stigma-in-state/articleshow/75071886.cms (Accessed 6.2.20) [Google Scholar]

41. Kang L, Li Y, Hu S, Chen M, Yang C, Yang BX, Wang Y, Hu J, Lai J, Ma X, Chen J, Guan L, Wang G, Ma H, Liu Z (2020) The mental health of medical 
workers in Wuhan, China dealing with the 2019 novel coronavirus. Lancet Psychiatry 7(3):e14. https://doi.org/10.1016/S2215-0366(20)30047-X Epub 2020 February 5. PMID: 32035030; PMCID: PMC7129673

42. Bjelland I, Krokstad S, Mykletun A, Dahl A, Tell G, Tambs K (2008) Does

higher education protect against anxiety and depression? The HUNT study. Soc Sci Med (1982) 66(6):1334-1345. https://doi.org/10.1016/j.socscimed.2 007.12.019

\section{Publisher's Note}

Springer Nature remains neutral with regard to jurisdictional claims in published maps and institutional affiliations.

Submit your manuscript to a SpringerOpen ${ }^{\circ}$ journal and benefit from:

- Convenient online submission

- Rigorous peer review

- Open access: articles freely available online

- High visibility within the field

- Retaining the copyright to your article

Submit your next manuscript at $\boldsymbol{\wedge}$ springeropen.com 